\title{
Single plasmon-active optical fiber probe for instantaneous chiral detection
}

Elena Miliutina $^{a, b}$, Olga Guselnikova ${ }^{a, b}$, Anna Kushnarenko ${ }^{a}$, Polina Bainovaa ${ }^{a}$, Pavel Postnikov ${ }^{a, b}$, Vladimír Hnatowicz ${ }^{\mathrm{c}}$, Vaclav Svorcik ${ }^{a}$, Oleksiy Lyutakov $* a, b$

a Department of Solid State Engineering, University of Chemistry and Technology, 16628 Prague, Czech Republic

${ }^{b}$ Research School of Chemistry and Applied Biomedical Sciences, Tomsk Polytechnic University, Russian Federation

${ }^{c}$ Institute of Nuclear Physics, Czech Academy of Sciences, 25068 Rez near Prague, Czech Republic

*Corresponding author: lyutakoo@vscht.cz

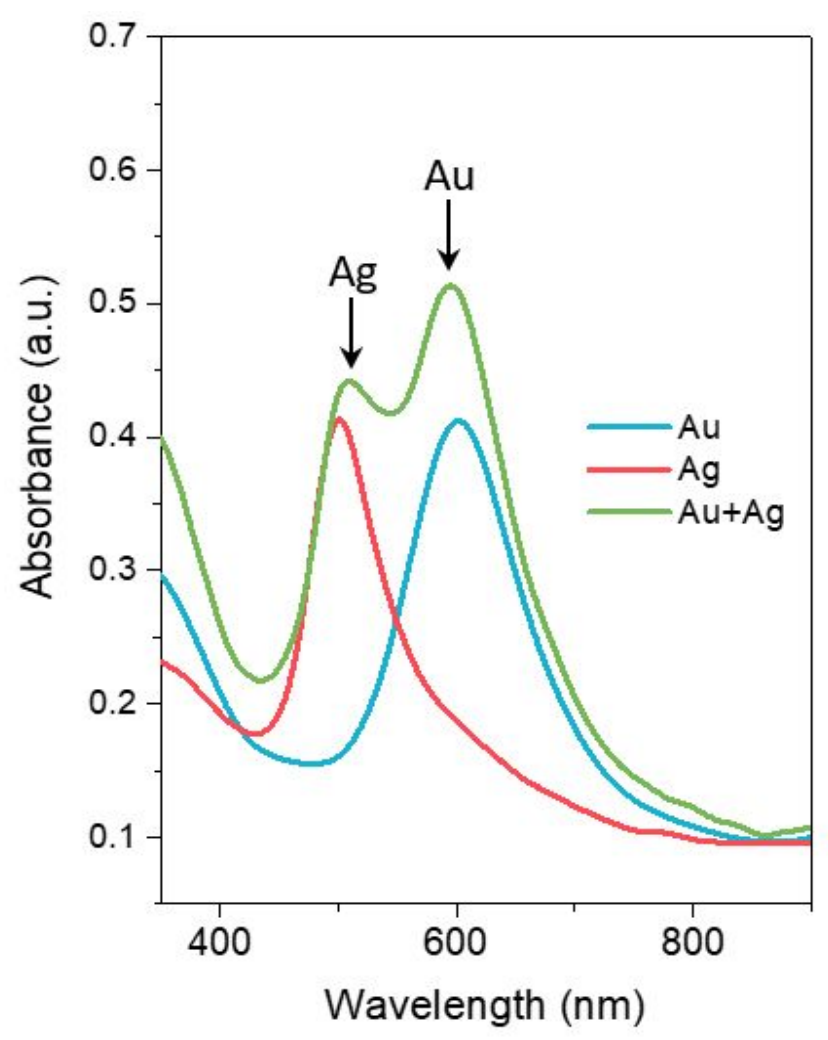

Fig. S1 Plasmon absorption bands, measured in reflection mode on plasmon fiber covered with $\mathrm{Au}$, $\mathrm{Ag}$, and both (spatially separated) metals 
Table S1. Results of XPS measurements on Ag and Au surfaces as a function of surface modification: (i) by $-\mathrm{C}_{6} \mathrm{H}_{4}-\mathrm{NH}_{2}$, (ii) $L$ - TA and (iii) $L$ - or $D$-DOPA enantiomers entrapping

\begin{tabular}{|c|c|c|c|c|c|}
\hline \multirow[t]{2}{*}{ Sample } & \multicolumn{5}{|c|}{ Surface atom element concentration (at \%) } \\
\hline & $\mathbf{C}$ & $\mathbf{O}$ & Ag & Au & $\mathbf{N}$ \\
\hline Pristine Ag & 28.9 & 9.8 & 61.3 & - & - \\
\hline $\mathrm{Ag} / \mathrm{C}_{6} \mathrm{H}_{4}-\mathrm{NH}_{2}$ & 46.7 & 12.3 & 35.6 & & 5.4 \\
\hline Ag / L-TA & 72.6 & 14.9 & 12.1 & - & 0.4 \\
\hline Ag / L-TA + L-DOPA & 78.3 & 19.5 & 1.4 & - & 0.8 \\
\hline Ag / L-TA + D-DOPA & 72.9 & 15.1 & 11.6 & - & 0.4 \\
\hline Pristine Au & 30.3 & 11.5 & - & 58.2 & - \\
\hline $\mathrm{Au} / \mathrm{C}_{6} \mathrm{H}_{4}-\mathrm{NH}_{2}$ & 46.3 & 14.5 & - & 34.3 & 4.9 \\
\hline Au / D-TA & 70.8 & 15.3 & - & 13.4 & 0.5 \\
\hline Au / D-TA + D-DOPA & 78.2 & 19.3 & - & 1.8 & 0.7 \\
\hline Au / D-TA + L-DOPA & 71,1 & 15.6 & - & 12.8 & 0.5 \\
\hline
\end{tabular}
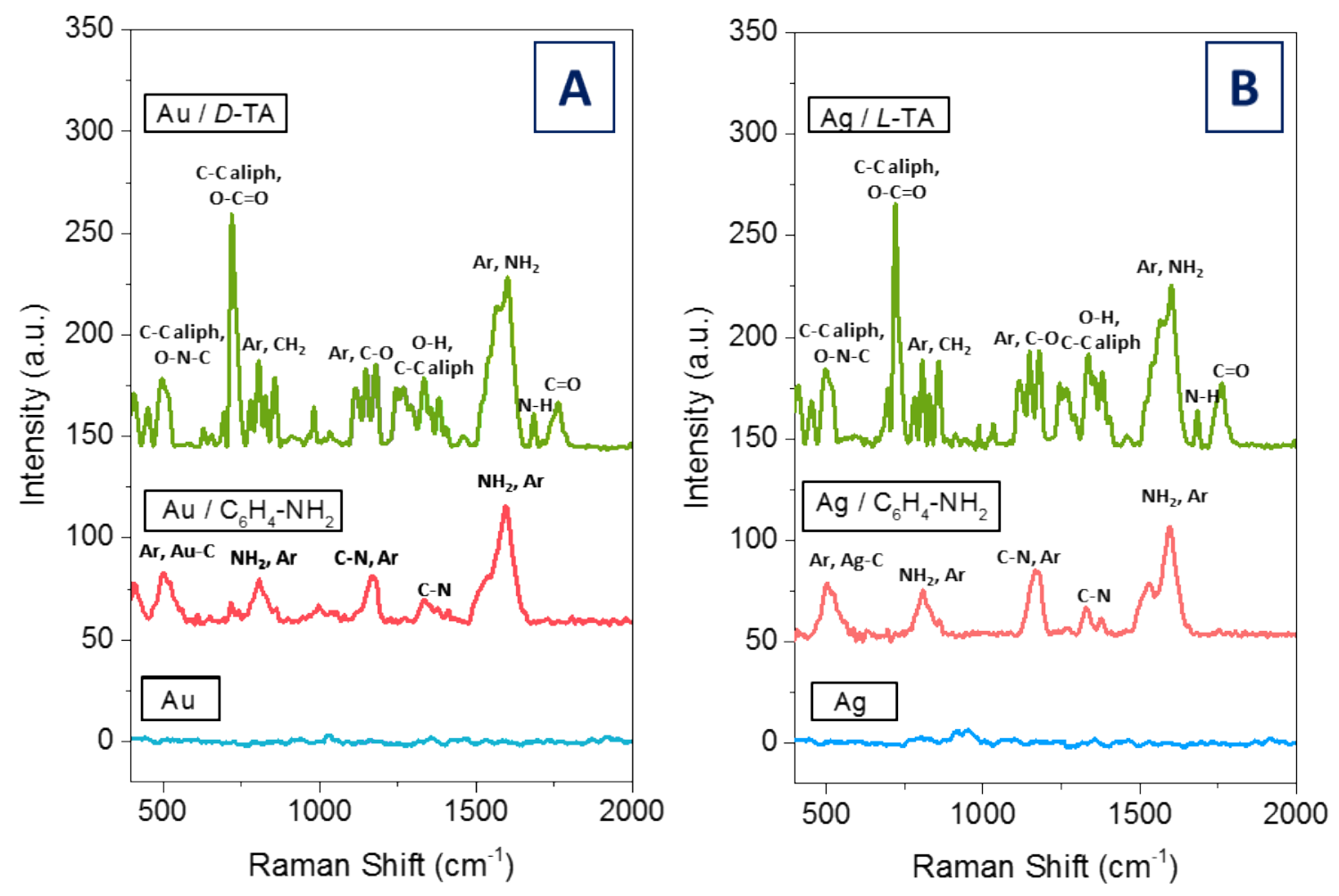

Fig. S2 Raman measurements performed on Ag and Au surfaces as a function of TA grafting steps 

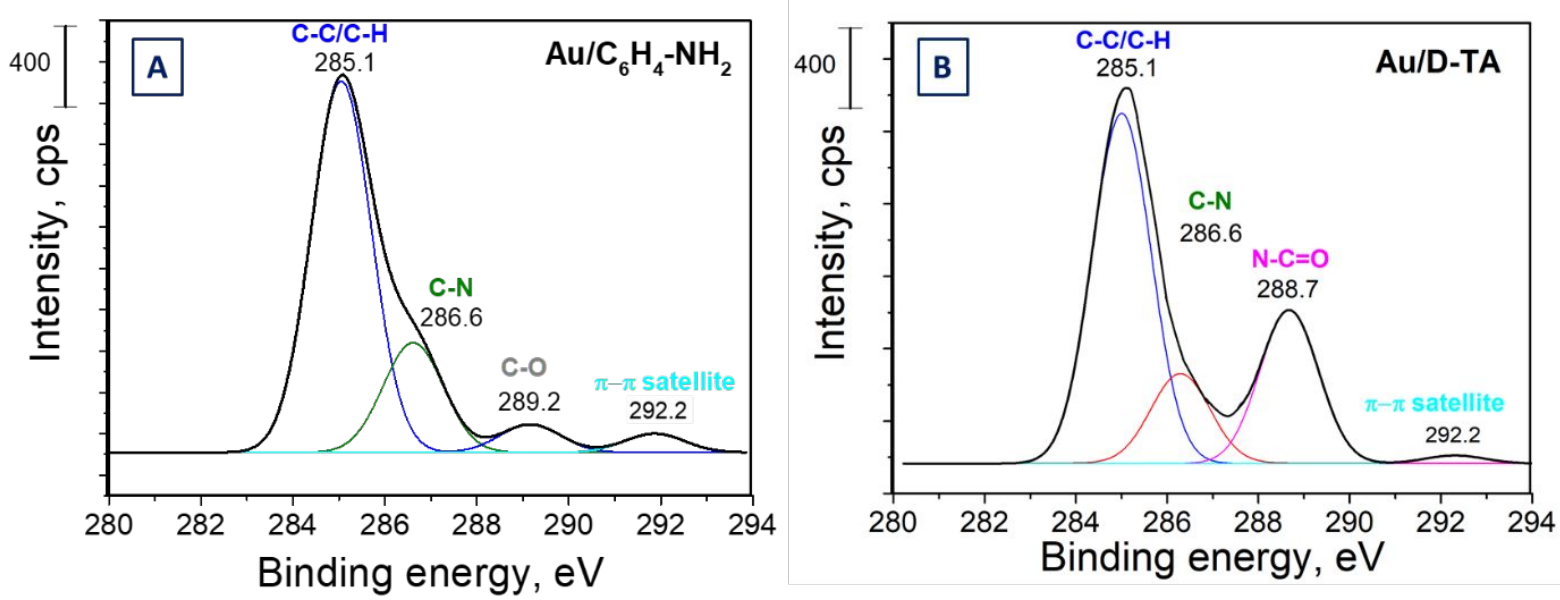

Fig. $\mathbf{S 3} \mathrm{C} 1 \mathrm{~s}$ region for a) gold surface modified by ADT-NH $\mathrm{H}_{2}$ and b) after grafting of $D$-TA. 


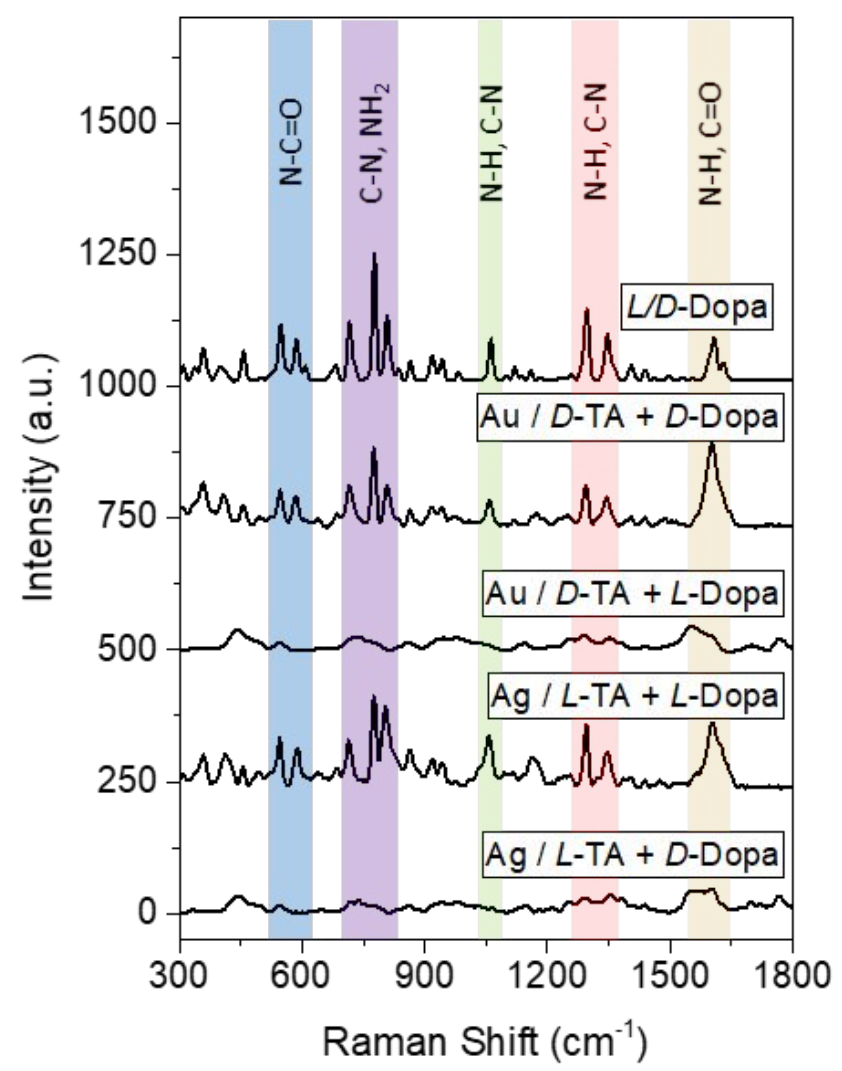

Fig. S4 Raman proof of DOPA selective entrapping (spectra were baseline corrected through the subtraction of $\mathrm{Au} / \mathrm{TA}$ or $\mathrm{Ag} / \mathrm{TA}$ spectra). 

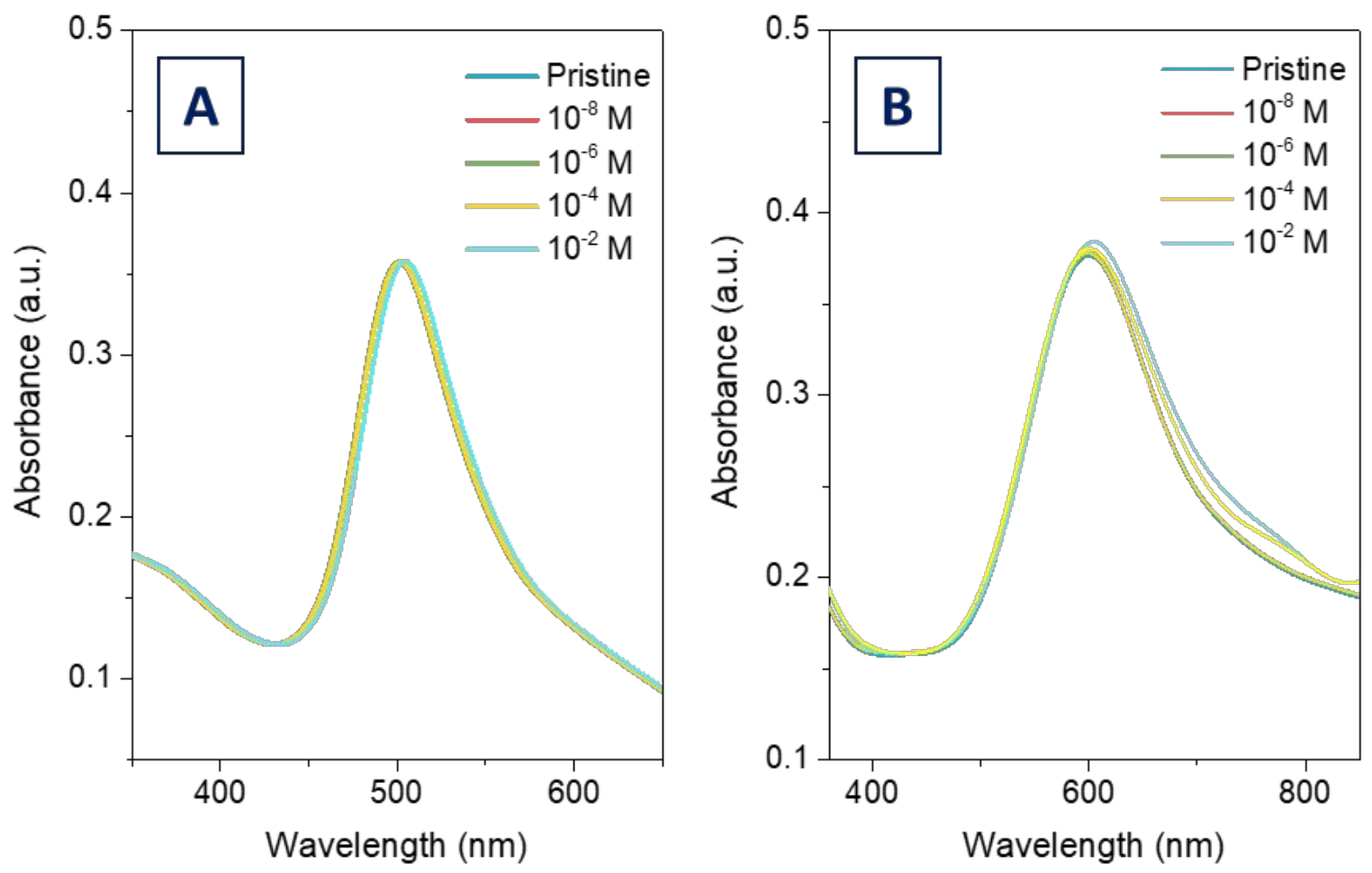

Fig. S5 Control measurements: wavelength positions of plasmon absorption bands of ungrafted Ag (A) and ungrafted Au (B) in the DOPA solutions. 


\section{Calculation of fiber-probe costs}

Thickness of gold - $50 \mathrm{~nm}$

Thickness of silver $-50 \mathrm{~nm}$

Fiber diameter - $200 \mu \mathrm{m}$

Metals volumes:

1) $\mathrm{Au}=0.000157 \mathrm{~mm}^{3}$;

2) $\mathrm{Ag}=0.049157 \mathrm{~mm}^{3}$

Metals weights:

1) $\mathrm{Au}=0.000003 \mathrm{~g}$

2) $\mathrm{Ag}=0.000516 \mathrm{~g}$

The market price of gold - the cost of 1 gram of gold is approximately 43.1 EUR. In regard to the weight of gold, deposited on the single-fiber probe the total gold cost is $\approx 2.12$ EUR.

The market price of silver - cost of 1 gram is approximately 0.52 EUR. In regard to the weight of silver, deposited on single-fiber probe the total silver cost $\approx 0.000268$ EUR.

Fiber cost is 164 EUR for 200 meters. For the preparation of one sensor, the $12 \mathrm{~cm}$ optical fiber length is needed. So that, the cost of fiber to one sensor is 0.1 EUR.

Total probe cost (without the costs of staff and equipment) $\approx 2.3$ EUR. 